\title{
D/VChikyu RISER OPERATIONS AND THE FUTURE OF SCIENTIFIC OCEAN DRILLING
}

BY DANIEL CUREWITZ AND ASAHIKO TAIRA

Earth science disciplines focused on investigation of climatic, ecological, or tectonic change as recorded in geological deposits (e.g., paleoceanography, marine micropaleontology, paleoclimatology, paleomagnetism) require high-resolution, continuous, well-preserved records for accurate analysis. Recovery of long, uninterrupted, relatively undisturbed sections has long been a primary technical challenge for any drilling operation. Recovered cores and geophysical measurements form the backbone for any further data collection and data analysis. Limitations on core recovery, core condition, and sample preservation have long been recognized as serious challenges for any reconstructions or interpretations of

Daniel Curewitz (daniel@jamstec.go.jp) is Staff Scientist, Center for Deep Earth Exploration (CDEX), Japan Agency for Marine-Earth Science and Technology (JAMSTEC), Yokohama, Kanazawa, Japan. Asahiko Taira is Director-General, Center for Deep Earth Exploration, Japan Agency for Marine-Earth Science and Technology, Yokohama, Kanazawa, Japan. the geological record.

Advances in scientific drilling over the last decade have enabled progressively better recovery and greater confidence in the fidelity and coherence of recovered sections. The resulting interpretations and analyses have enhanced the highresolution short- and long-term records of changes in the Earth system (Brewer et al., 2005).

The adaptation of riser drilling technology for scientific ocean drilling purposes on board the D/V Chikyu (Figure 1) represents a giant step forward for the scientific ocean drilling community. The D/V Chikyu is operated by the Center for Deep Earth Exploration of the Japan Agency for Marine-Earth Science and Technology. The use of this state-ofthe-art drilling and coring system as one of the principal platforms in the Integrated Ocean Drilling Program (IODP) will advance the science of reconstructing past environments and analyzing Earth system evolution as recorded in the sediments and rocks below the ocean floor. In the following discussion, we enumerate the technological and op- erational means by which core recovery, core preservation, borehole stability, geophysical measurement, and borehole monitoring operations are enhanced using riser drilling (Sawyer, 1996; Kerr and Normile, 1998; Normile and Kerr, 2003).

\section{RISER DRILLING BASICS}

Riser drilling involves several steps that are accomplished in a variety of ways depending on specific technological packages, water depths, and bottom conditions. First, a wide-diameter pilot hole is drilled and cased, then a specialized wellhead designed to anchor a pressure sensor and shut-off valve assembly, called a Blow Out Preventer (BOP; Figure 2), is installed. The BOP itself is lowered to the wellhead and attached using a Remotely Operated Vehicle (ROV). Lowering of the BOP is accomplished by successively attaching riser pipe (Figure 3 ) to the top of the BOP and lowering it to the seafloor. Riser pipe itself comprises wide-diameter, high-strength pipe with external conduits for cables and connectors to allow control and monitoring of the BOP. Once the BOP is installed at the wellhead 

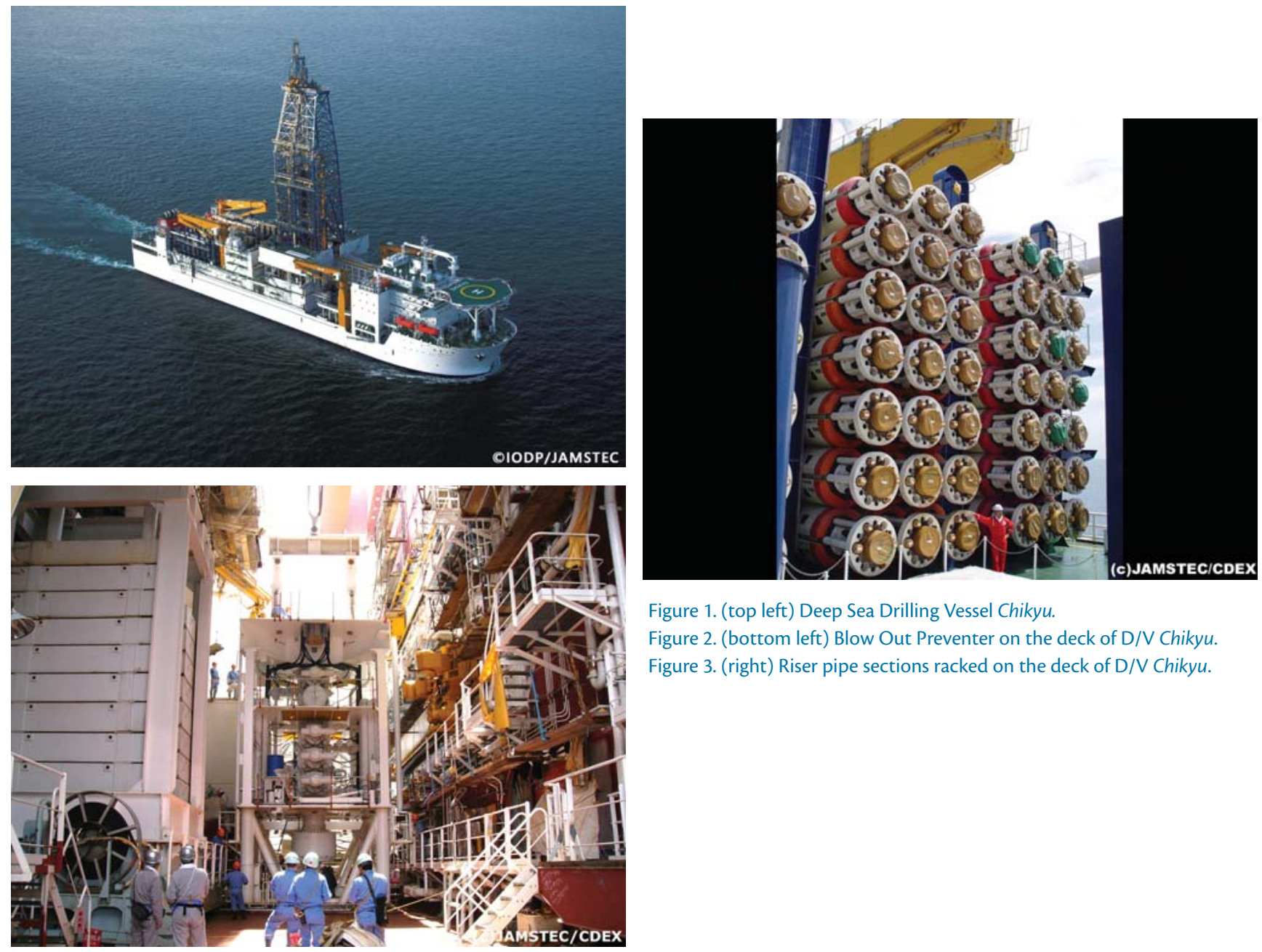

Figure 1. (top left) Deep Sea Drilling Vessel Chikyu.

Figure 2. (bottom left) Blow Out Preventer on the deck of D/V Chikyu. Figure 3. (right) Riser pipe sections racked on the deck of D/V Chikyu.

and linked to the drilling vessel via the riser pipes, drilling and coring (as well as any downhole logging, measurement, or sampling) operations begin (Brewer et al., 2005).

The drillstring (drill pipe, drill bit, and any attached equipment, sensors, or tools) is lowered into the borehole entirely inside the riser pipe. Drilling mud (a high-density, chemically inert, fluidized mixture tailored to match the ambient geological fluid- and gas-pressure conditions) is pumped into the borehole inside the drillstring. Drilling mud specifically designed for coring operations, called "coring mud" or "bland coring mud," can be used when preservation of porosity/permeability structures or reduced chemical contamination of the cored formations is required. Drilling/coring mud exits the drill pipe at the drill bit, and returns through the riser pipe (outside the drillstring) to the drilling vessel, carrying with it suspended cuttings, fluids, and gases derived from the drilling process and from the pen- etrated formations (Figure 4).

The drilling mud is filtered through a graduated series of screens (called "shale shakers"), removing drilling cuttings and other fragments (e.g., borehole-wall collapse fragments, which are distinguished from cuttings based on physical appearance). These cuttings are then available for geological and physical properties examination and interpretation, including lithology, geochemistry, paleontology, consolidation, $\mathrm{p}$-wave, and porosity/density analysis. Gases and fluids trapped 


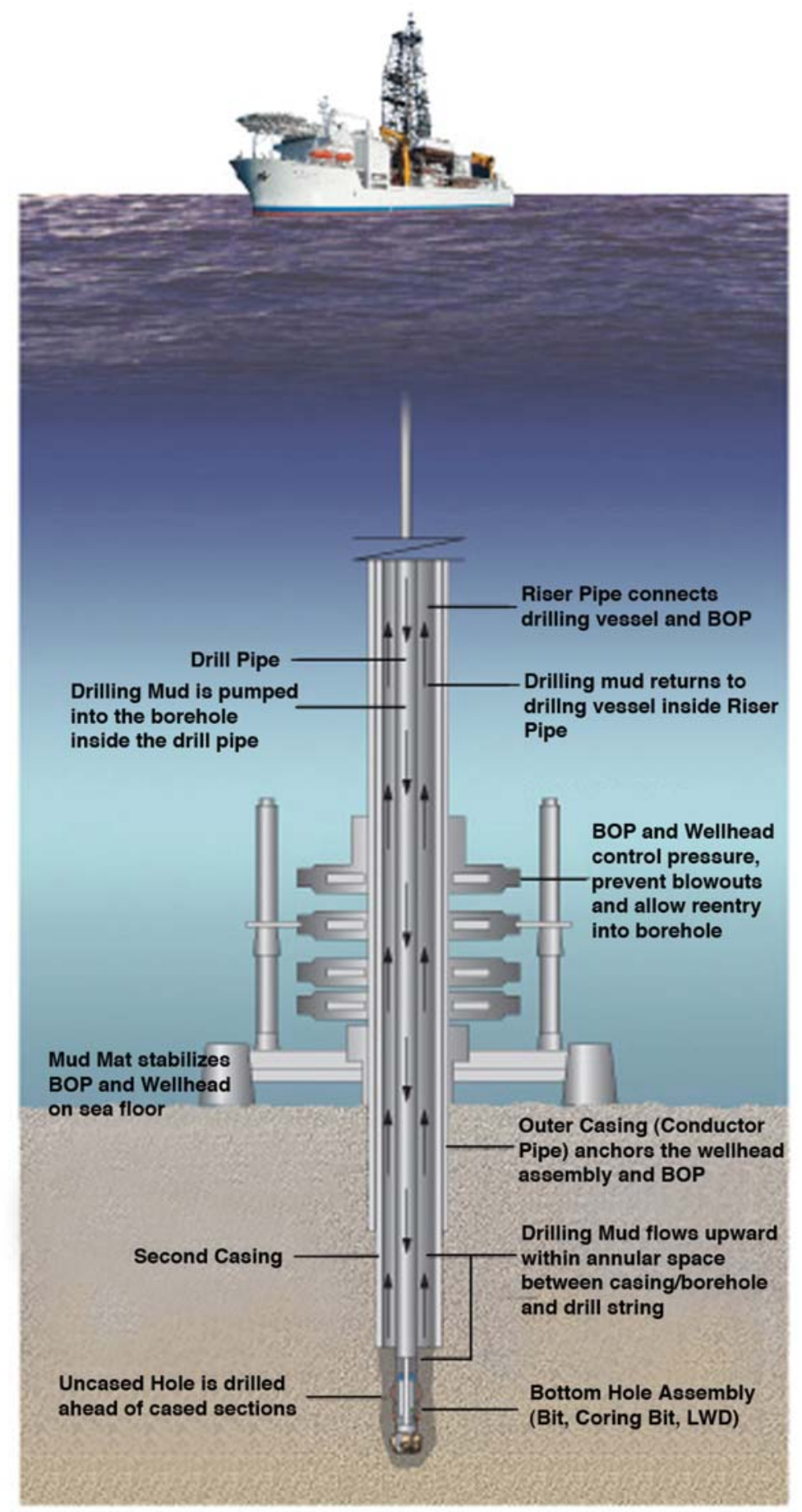

Figure 4. Diagrammatic depiction (modified after Sawyer, 1996) of riser drilling operations showing the borehole, the wellhead, the BOP, and the riser pipe connecting to the drilling vessel. Drilling mud flows down through the drillstring, exits at the drill bit, and is returned in the annular space between the drillstring and the riser pipe walls. in the drilling mud are also collected for chemical analysis for both safety and scientific purposes. The filtered drilling mud is then cycled back into the drilling operation. As drilling progresses, the chemical composition of the drilling mud is altered to compensate for increased lithostatic stress, gas pressure, hydrocarbon deposits, fault zones, and/ or fractured intervals (Yano et al., 2001).

\section{RISER DRILLING ADVANTAGES}

Recirculation of high-density drilling fluid through the borehole enhances the drilling and coring operations in a variety of ways (Adamson et al., 1998). First, the density of the drilling fluid is calibrated using preexisting and realtime information about the properties of the penetrated geological formation, including gas and fluid pressures, fracture density, porosity and permeability, and physical characteristics of the rocks. Drilling-fluid density is tailored to prevent borehole collapse, gas blowout, or excessive fluid flow in the borehole, increasing the safety and efficiency of the drilling operation. Additionally, rock fragments produced by drilling and coring are carried away from the drill bit by the high-density fluid, reducing the risks of jamming the drill bit and producing a cleaner borehole, both for drilling and for later downhole operations. Temperature and friction at the drill bit are reduced, increasing the life span of each bit, while increasing potential drilling speed and enhancing both core recovery and core quality. This combination of advantages allows increased performance throughout the entire drilling operation, discussed below. 


\section{Deeper Boreholes}

The circulation of high-density drilling fluid increases borehole stability and reduces the possibility of borehole wall collapse or constriction. Riser boreholes can potentially be drilled to depths of 7,000 meters or more. Reduced bit wear, elimination and/or reduction of bit jamming or drillstring constriction, and elimination of loose fragments in the borehole contribute to this expanded depth range. Prior experience in scientific ocean drilling with non-riser systems indicates that boreholes are limited to $\sim 2,000$-meter depths due to the combination of borehole collapse, constriction, and fragment-related bit jamming.

\section{Enhanced Core Recovery}

Reduced friction at the drill bit, reduction of the number and volume of rock fragments, prevention of borehole collapse and constriction, and smoothing of the entire drilling process should ensure enhanced core recovery, both in terms of percent recovery and in terms of the quality of the cores recovered. Riser drilling enhancements to core recovery should be most marked during rotary coring in consolidated sediments or hard rock (as opposed to hydraulic piston coring operations in soft sediments).

\section{Borehole Preservation and Stability}

Riser drilling provides for enhanced borehole quality both during drilling and in post-drilling (e.g., downhole measurement) operations. Stabilizing the borehole by preventing collapse, constriction, or fluid/gas blowout enables clean and efficient drilling and coring, and removes risks associated with rock fragments and borehole deformation. Riser drilling also improves the ability to ream and case completed boreholes by enabling rapid clearing of fragments, preventing borehole collapse, and reducing the risks of cavity creation that may occur during hole-opening operations. These operations improve the feasibility and success rate of logging operations in open holes (directly following drilling operations), and increase the viability and feasibility of downhole measurement and monitoring operations using either CORK (borehole seal; see Kastner et al., this issue) or CORK-like equipment packages or downhole sampling and measurement tools. In addition, reentry and re-occupation of existing boreholes drilled with riser technology have a greater success rate due to the initial high-quality borehole.

\section{Long-Term Monitoring, Reentry,} and Borehole Instrumentation The stability of the borehole, the quality of the casing procedure, and the conditions both inside the borehole and in the penetrated formations are critical to the success or failure of operations that take place following the completion of drilling and coring operations. The installation of packers, fluid pressure monitoring devices, geochemical sensors, and downhole packages of strain, tilt, or seismic measurement devices is entirely dependent on the condition and preservation of the borehole. Riser drilling increases the probability that a given borehole will be suitable for such operations by increasing the borehole stability over long periods of time.
Operations in Gas- or Fluid-Rich Formations

Riser drilling using high-density drilling fluid was initially developed in the oil industry to reduce the risks of blowout resulting from penetration of overpressured formations. Ocean Drilling Program (ODP) operations were, by necessity, restricted from drilling in areas thought to host gas, oil, or other potentially pressurized fluid deposits or conduits. As a result, drilling in active fault zones, methane-hydrate-rich regions, or any areas characterized by high possibility for hydrocarbon deposits was limited by requirements for densely spaced, high-quality, site-specific hazard survey data analyzed and available before any drilling could take place. The adoption of oil industry, riser-based technology for scientific drilling will permit operations in areas that were previously offlimits or extremely restricted.

Operations in Highly Fractured or Friable Formations

The use of drilling fluid to clean and stabilize the borehole during drilling, and to enable rapid and effective reaming and casing of boreholes will enhance the ability to drill, core, log, and monitor in fragile, fractured, or friable rock formations such as sand-rich turbidite deposits, fractured basalt layers, and/or highly fractured fault zones. Prior ODP operational experience indicated that non-riser drilling was limited and prone to being compromised in these kinds of rock formations, mostly as a result of jamming of drill bits and borehole collapse. Drilling with a riser will allow more comprehensive and high-resolution rock and geophysical measurements 
in a wide array of formations that were previously either un-drillable or were expensive and risky.

\section{Sample Integrity}

In addition to the basic physical integrity of the core samples derived from the increased speed, efficiency, and quality of drilling operations, the core samples and sub-samples from cores collected during riser drilling operations may be better preserved for biological, biochemical, and/or geochemical analysis. The riser hole is isolated from the seafloor environment once the BOP is installed and sealed, and all circulation within the borehole is controlled via the shipboard pumping system. The chemical composition of the drilling fluid is also known and closely monitored for safety and drilling reasons. The result, in terms of chemical or biological investigation, is that contamination of the cores and samples can be better monitored and understood, allowing for improved understanding of geo-bio-chemical systems.

\section{Mud, Cuttings, Mud-Gas, and Fluid Logging}

The return flow of drilling fluid to the ship is monitored for gas and fluid contamination with respect to the known composition of the original mixture pumped into the borehole, and is sequentially screened to smaller and smaller clast sizes in order to collect any fragment samples returned to the vessel. Gas and fluid carried back to the vessel by the drilling mud are captured and monitored for safety purposes. Scientific analysis of cuttings and gas/fluid is currently employed in a variety of drilling operations. The timing of ascent of a given batch of cuttings can be translated into a rough depth estimate, allowing the correlation of cuttings to depth to within $\sim 1$ - to 10-meter resolution. Mud, mud-gas, and cuttings analyses thus add both safety and analytic components to the scientific drilling operation-data from cuttings and gas/fluid analyses contribute to the understanding of the geology and geophysics of the borehole. While these measurements are definitely of lower resolution than core or log data, they have the potential to fill gaps in recovery, to strengthen correlations made between cores and log data, and to add significantly to the understanding of gas and fluid conditions in the borehole.

\section{SUMMARY AND FUTURE DIRECTIONS}

The addition of riser capability to the scientific drilling toolbox will enhance the ability to drill to greater depths with better recovery, produce more stable, long-lived boreholes suitable for reentry and long-term monitoring operations, and allow drilling, coring, and monitoring in an array of geological environments that were previously inaccessible to the scientific drilling community. The ability to monitor and sample mud-gas, fluids, and cuttings adds another layer of analytical and data collection capabilities and will help to enhance our ability to integrate drilling information, corederived data, and logging data, and may enhance the ability to integrate these data with geophysical analyses.

The current riser-drilling capability on board the D/V Chikyu is limited to water depths greater than 500 meters and less than 2,500 meters due to safety requirements and the physical strength and weight limitations of the riser pipe. Ongoing research and development in the hydrocarbon industry coupled with academic efforts and design initiatives within IODP and CDEX are aimed at expanding this envelope to enable riserdrilling operations in waters deeper than 2,500 meters. Other ongoing initiatives, some adapted from the hydrocarbon industry, are aimed at capitalizing on the advantages gained by the use of riser drilling, including advanced long-term monitoring and telemetry packages, downhole sampling and measurement techniques, and incorporation of advanced techniques such as logging and measuring while drilling.

Together these innovations and technical advances will broaden the frontiers of ocean drilling science by opening up new areas for analysis and investigation in a wide array of geological settings. ⿷匚

\section{REFERENCES}

Adamson, K., G. Birch, E. Gao, S. Hand, C. Macdonald, D. Mack, and A. Quadri. 1998. Highpressure, high-temperature well construction. Oilfield Review 10(2):36-49.

Brewer, T., T. Endo, M. Kamata, P.J. Fox, D. Goldberg, G. Myers, Y. Kawamura, S. Kuramoto, S. Kittredge, S. Mrozewski, and F. Rack. 2005. Scientific deep-ocean drilling: Revealing the Earth's secrets. Oilfield Review 16(4):24-37.

Kerr, R.A., and D. Normile. 1998. Ocean drilling floats ambitious plans for growth. Science 282(5392):1,251-1,252, doi: 10.1126/science.282.5392.1251.

Normile, D., and R.A. Kerr. 2003. A Sea Change in Ocean Drilling. Science 300(5618):410-412, doi: 10.1126/science.300.5618.410.

Sawyer, D. 1996. Post-2003 talk about ODP is on the rise. JOI/USSAC Newsletter 9(3):1-3, 19-22. Yano, Y., M. Kyo, S. Takagawa, and Y. Tsuritani. 2001. Development of Scientific Riser Vessel. UJNR Marine Facilities Panel, 24 $4^{\text {th }}$ Joint Meeting Report. [Online] Available at: http://www.nmri. go.jp/main/cooperation/ujnr/24ujnr_paper_ jpn/Yano.pdf [last accessed October 11, 2006]. 